Article

\title{
Implementing the Prepaid Smart Meter System for Irrigated Groundwater Production in Northern China: Status and Problems
}

\author{
Xiaowei Wang ${ }^{1}$, Jingli Shao ${ }^{1, *}$, Frank van Steenbergen ${ }^{2}$ and Qiulan Zhang ${ }^{1}$ \\ 1 School of Water Resource and Environment, China University of Geosciences, Beijing 100083, China; \\ wangxw@cugb.edu.cn (X.W.); qlzhang919@cugb.edu.cn (Q.Z.) \\ 2 Meta-Meta Research, Postelstraat 2, 5211 EA's-Hertogenbosch, The Netherlands; \\ fvansteenbergen@metameta.nl \\ * Correspondence: jshao@cugb.edu.cn; Tel.: +86-10-8232-3499
}

Academic Editor: Sharon B. Megdal

Received: 10 March 2017; Accepted: 23 May 2017; Published: 28 May 2017

\begin{abstract}
To reduce the gap between groundwater demand and supply caused by agricultural groundwater over-exploitation, the Prepaid Smart Meter System (PSMS) is being strongly implemented by the Chinese government in northern China. This study reports the analysis and results of PSMS field surveys in six typical provinces in northern China as well as domestic literature reviews. Based on the architecture and implementation policies of the system, the implementation differences between areas and the influencing factors were analyzed, particularly the acknowledgment of farmers, the installation proportion of tube wells, the social benefits. Great achievements have been gained in the implementation, and the management targets have been achieved, including accurately metering overall irrigation groundwater production, assisting in the total amount control and quota management, reducing groundwater exploitation, and improving water use efficiency. However, shortcomings remain in the implementation process, such as single initial investment channels, imperfect policy system construction, a lack of retrieving and analyzing data, and the unbalanced development between areas. Countermeasures and suggestions for these problems are discussed in this article.
\end{abstract}

Keywords: groundwater abstraction; northern China; Prepaid Smart Meter System

\section{Introduction}

The arid and semi-arid areas of northern China are prosperous due to a large population and rapid economic growth; however, available water resources are insufficient for development and the deficit between water demand and supply is growing. Groundwater is important for China's water supply [1-3], especially in the northern China provinces. Groundwater supply accounts for more than half of the water resource supply in provinces such as Hebei, Henan, Beijing, Shanxi, and Inner Mongolia [4]. Due to the spatial-temporal distribution characteristics of precipitation, the irrigated agricultural areas primarily located in northern China experienced a rapid expansion after the 1970s. More than half of the cultivated areas are under an irrigation scheme and over $75 \%$ of the crop output is generated from irrigation in the Yellow River Basin, Haihe River Basin, and Huaihe River Basin [5]. Crops were increasingly harvested using this strategy [2,6], and groundwater consumption increased to meet the irrigation demands. Groundwater demand is also continually increasing due to urbanization, including the two large cities of Beijing and Tianjin and the construction of industries and mines. Groundwater resources are not abundant in the plain areas of northern China, which only contains 1/3 of the nation's groundwater resources [4]. Groundwater was significantly overexploited in northern 
China due to the water shortage stress from irrigation and social development. In the North China Plain (NCP), statistics and simulation results demonstrated that approximately $200-250 \times 10^{8} \mathrm{~m}^{3}$ of groundwater was pumped during 2000-2008 [7,8], but the regional recharge amount was only approximately $165 \times 10^{8} \mathrm{~m}^{3} /$ a during the same period [9].

Groundwater over-exploitation had led to serious hydro-environmental and geo-environmental problems. Problems such as continual groundwater level decline as well as significant land subsidence and seawater intrusion occurred in the NCP where water supply, grain supply, and geological security had been severely threatened and gained extensive attention domestically and abroad [10-16]. Other cases occured in the Northwest Inland River Basins of China, where the ecological condition is fragile. Critical ecological degeneration, such as desertification, wetlands shrinkage, and groundwater quality deterioration [17-19], were caused by groundwater over-production.

Climate change is predicted to deteriorate the water resources and aggravate conflicts among water users [20]. Irrigation water resource shortage problems are universal not only in China but also in agriculturally developed countries around the world, especially in arid and semi-arid areas [21-23]. To offset the water deficit and improve the efficiency of water utilization, the Groundwater Demand Management (GDM) tool had been used in many countries [24-26]. China also introduced and implemented the concept of GDM [27-29]. After years of controlling the total amount and quota management of water resource consumption, the Chinese government refined a comprehensive water resource management idea that was identified as the Strictest Water Resources Management System in 2011. It is formulated to fully control the total groundwater consumption amount [30].

The primary problem in implementing GDM at a local level is that groundwater production lacks monitoring and statistics because of the large number and distribution of tube wells. Using the Hebei Province as an example, the effective irrigated area was $43,490 \mathrm{~km}^{2}$ by the end of $2013,85 \%$ of which was tube well irrigated areas, and the total tube wells reached $9.14 \times 10^{5}$ [31]. Nearly all the wells were owned and operated individually and did not apply for production permits. This indicated that tube well management, such as drilling, permitting, monitoring, and abandonment by the local government was necessary. The Chinese government decided to implement the Prepaid Smart Meter System (PSMS) to monitor and manage groundwater irrigation comprehensively and achieve GDM. This process attracted significant attention from the Food and Agriculture Organization of the United Nations [32].

To directly manage water resources, PSMS has been adopted for agricultural utilization around the world, especially in developing countries such as Iran, Bangladesh, Oman, India, etc. [33-38]. The PSMS has many advantages for agriculture, including the following: (1) Farmers can accurately obtain their water consumption rate; (2) Basic data can be supplied to government managers for total water amount control and for statistical analysis at different scales; (3) Due to the water consumption variances of crops, the government can optimize the planting location according to the observed water production to conserve water; (4) Quota management can be implemented by presetting the quota in the system; (5) Farmers can be encouraged to modify their water consumption practices to reduce costs by improving water use efficiency and decreasing waste; (6) Once the exact quota is recorded, the transferring and trading of water rights will be feasible not only between the government and farmers but also between the farmers, agriculture, and industry; (7) Wireless and immediate data transmission is designed in the system, which can help reduce the cost and mistakes of manual transcription, improving management efficiency; (8) The system can be combined with other management tools for better results, for instance, associating this tool with differential pricing policies can further promote water conservation. The PSMS also has shortcomings as follows: (1) The system implementation has a high cost that requires a large initial investment for the overall installation; (2) It is difficult to maintain due to the distributed production wells; (3) The terminal facilities installed on the wells suffer significant natural and man-made damages under poor working conditions.

The PSMS was widely used both in urban and rural areas; although existing PSMS studies focus on residential water user's behavior based on the PSMS data [39-42] and product development of the system, less attention was placed on the utilization of the PSMS for agricultural use. The research and 
implementation of the PSMS in China can provide good feedback and lessons learned for domestic management and for other countries; however, reviews or reports are seldom found. This research comprehensively introduced the large-scale implementation of the PSMS in China since the end of the 20th century. The PSMS implementation process and status in northern China was presented and analyzed based on field surveys and interviews in six selected provinces and on domestic literature reviews. The shortcomings of PSMS implementation and management in China are discussed at the end as well as the management countermeasures.

\section{Study Area}

The study area is located in northern China, which has 17 provinces and a total area of $4775 \times 10^{6} \mathrm{~km}^{2}$, of which the plain area is $1506 \times 10^{6} \mathrm{~km}^{2}$. Figure 1 shows the study area region, spanning from $32^{\circ} \mathrm{N}$ to $53^{\circ} \mathrm{N}$ and from semi-humid to arid and semi-arid climatic zones. The average precipitation decreases from $800 \mathrm{~mm} / \mathrm{a}$ in the east coastal areas to less than $100 \mathrm{~mm} / \mathrm{a}$ in the west inland areas. Thick quaternary aquifers with large volumes of groundwater resources deposited in the plain areas, such as the North China Plain (NCP), Shanxi Basin, Northeast Plain, the northwest oasis, etc., supply abundant water resources for cultivation. These plain areas have been major grain producing resources in China since ancient times through the cultivation of wheat and corn.

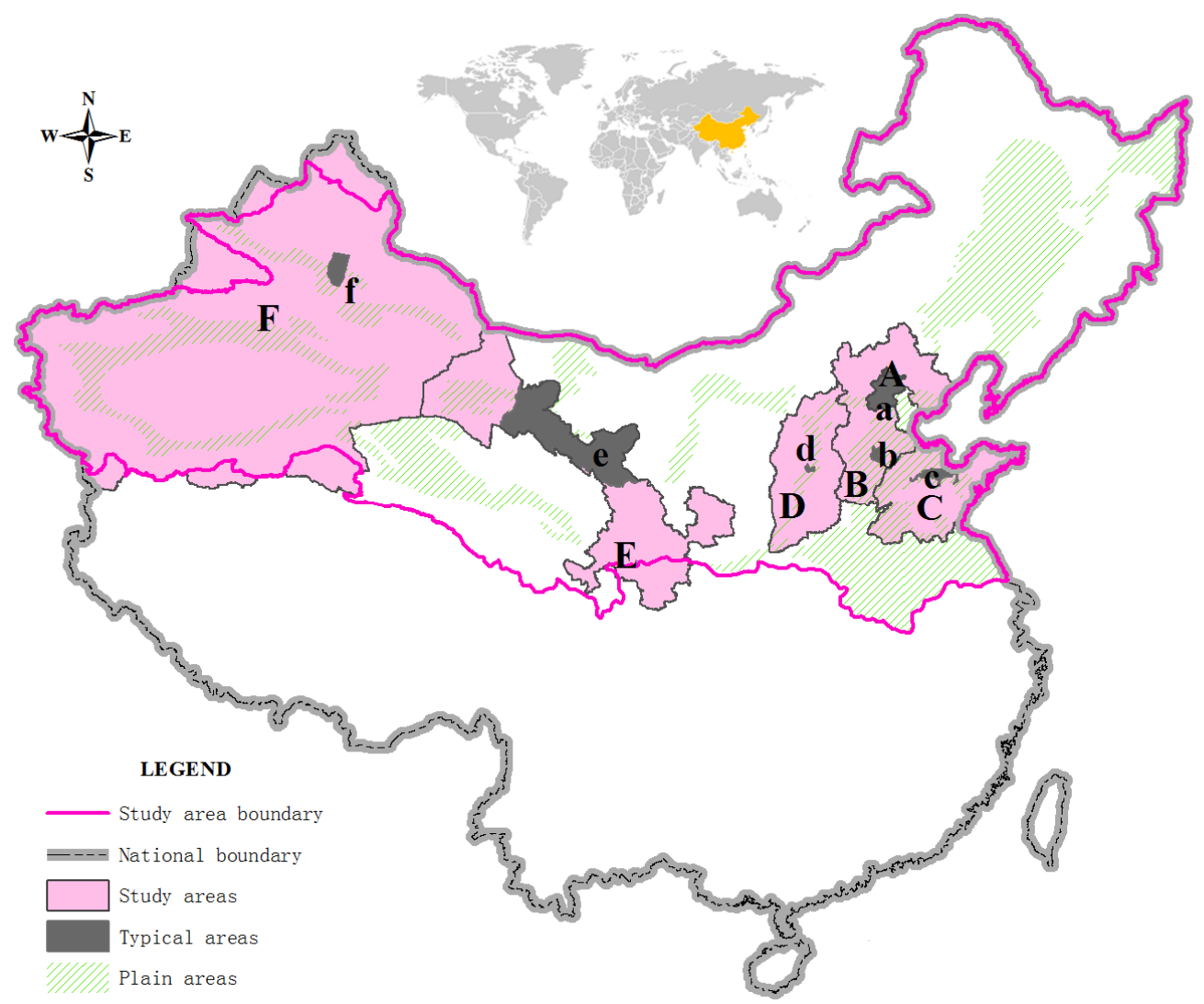

Figure 1. The northern China study area and the six selected provinces where groundwater over-production occurred in typical plain areas. A-Beijing, B-Hebei Province, C-Shandong Province, D-Shanxi Province, E-Gansu Province, F-Xinjiang Province, a-entirely covers Beijing, b-Taocheng County and Shenzhou County of Hengshui City, c-Zibo-Weifang groundwater depression cone, d-Qingxu County, e-Shiyang River Basin and Heihe River Basin, and $\mathrm{f}-$ Fukang County.

Compared to the large water demand and potential demand, the amount of water resource supplies in the study area is insufficient. With $13 \%$ of the country's water resources available, 
the eastern part of the study areas fosters $44 \%$ of China's population and $65 \%$ of its cultivated land [43]. Especially in the relatively well-developed NCP, although it only has $6.65 \%$ of the water resources in China, this region accounts for approximately $12 \%$ of China's GDP and more than $10 \%$ of China's total grain production $[44,45]$. Figure 2 shows that agricultural water consumption in northern China increased from $1700 \times 10^{8} \mathrm{~m}^{3} / \mathrm{a}$ to $2100 \times 10^{8} \mathrm{~m}^{3} / \mathrm{a}$ and accounted for approximately $75 \%$ of the total water consumption from 2003 to 2014 . The groundwater supply fluctuated from $880 \times 10^{8} \mathrm{~m}^{3} / \mathrm{a}$ to $1000 \times 10^{8} \mathrm{~m}^{3} /$ a during 2003-2010. The proportion of the groundwater supply compared to the total groundwater resources in the area increased from below 35\% to approximately $40 \%$ over the past 11 years. The proportion of the groundwater supply to the total water supply was maintained at approximately $36 \%$.

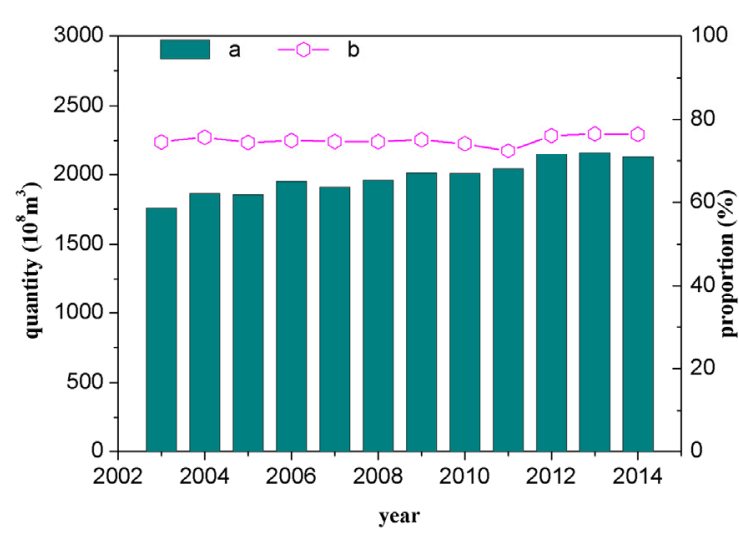

(a)

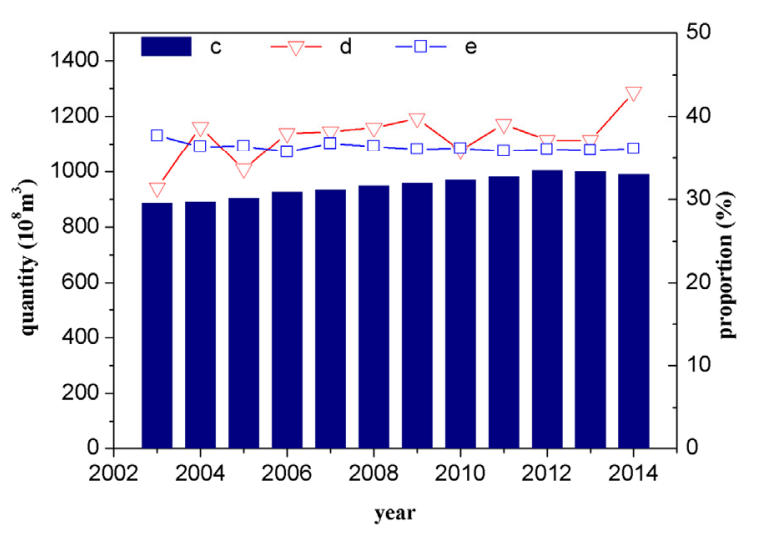

(b)

Figure 2. (a) Agricultural water consumption in northern China; (b) Groundwater conditions in northern China 1. a-agricultural water consumption quantity $\left(10^{8} \mathrm{~m}^{3} / \mathrm{a}\right), \mathrm{b}$ - the proportion of agricultural water consumption to the total water consumption (\%), c-groundwater supply quantity $\left(10^{8} \mathrm{~m}^{3} / \mathrm{a}\right), \mathrm{d}$ - the proportion of the groundwater supply to the total groundwater resources $(\%)$, e-the proportion of the groundwater supply to the total water supply (\%). ( Data from China Water Resources Bulletin 2003-2014 [4]).

\section{Materials and Methods}

Figure 1 shows the six typical areas that were selected. The collected first-hand materials comprised interviews with the local water bureau at each level, water bureau report materials, field surveys and interviews with farmers in the typical areas, the results from projects in which the authors participated, etc. (Table 1.)

In addition, approximately 100 domestic articles related to the PSMS were collected, 20 of which were selected due to their focus on agricultural PSMS implementation and management. The data and information in the articles were estimated with the materials acquired from the field surveys and interviews. 
Table 1. Summary of the material collection work.

Province Typical Areas

Beijing

Hebei

Taocheng County and Shenzhou County

Zibo-Weifang groundwater depression cone

Shiyang River Basin and Heihe River Basin
All the cantons of Beijing

\section{Working Details}

1. An interview was held with the operator of the Beijing Water Science and Technology Institute who is in charge of the technical support to implement the Prepaid Smart Meter System (PSMS) and discussions on the status and problems of the implementation were made in October 2014

2. A field survey was conducted in the Tongzhou District with farmer interviews in October 2014

1. Interviews were held with the water resources bureau of Taocheng County and Shenzhou County in Hengshui City in November 2014. Details on agricultural irrigation management and PSMS implementation as well as problems were discussed.

2. Field surveys and investigations were conducted in 15 selected villages in the Taocheng-Shenzhou area in the form of a questionnaire and interview to understand the status of PSMS promotion.

1. Interviews were held with the water resources bureau of Huantai County, Shouguang County, and Gaomi County within the depression cone to understand the status of PSMS implementation in 2014. A field survey was conducted in Huantai County with end user interviews.

2. Discussions were conducted with the water resources bureau for counties in the area to discuss issues related to the implementation of the system in October 2014.

3. Discussions were held with the water resources bureau of Shouguang County and Huantai County in the form of questionnaires in January 2015. Furthermore, a field survey was conducted for the terminal parts of the system and user interviews were held.

1. Grants from the Asian Development Bank Grant Project regarded as "Climate Change Adaptation Through

Groundwater Management in Shanxi Province" (Project Number: 0188-PRC), including information obtained from field surveys and interviews for the project operating from December 2010 to August 2013.

1. An investigation was conducted in the Shiyang River Basin in April 2014, including interviews with the provincial water resources bureau, basin management bureau, and local water resources bureau, as well as reports from the local water resources bureau and PSMS field surveys in the Quansh irrigation district in the baseports

2. An investigation was conducted in the Heihe River Basin in September 2014, including interviews with the provincial water resources bureau, basin management bureau, and local water resources bureau, as well as reports from the local water resources bureau, PSMS field surveys in the Luotuocheng irrigation district and Yingke irrigation district and communications with farmers.

3. A field survey was conducted in four towns and villages of Minqin County downstream of the Shiyang River Basin to understand the PSMS operation in April 2015 and discussions and communications with farmers were also held.
1. An investigation was held in Fukang County in March 2014. PSMS discussions were held with the county level water resources bureau who initially provided a report on their system.

2. A field survey was held in the town of Ziniquanzi for the operation of terminal facilities and the management center. 


\section{PSMS Status in Northern China}

The Chinese government committed to having all the irrigation wells controlled and measured in typical areas since the end of the 20th century. The PSMS was selected as the management tool to bring the distributed agricultural groundwater production into a unified control system. A further goal was to achieve total water amount control and quota management for agricultural groundwater consumption. During the more than 10-year development process, it was constantly developed and improved for not only the software and hardware structure of the PSMS but also for the supporting policies. A significant measurable achievement was also attained.

\subsection{System Architecture}

As a management system, the partners in the PSMS consist of many stakeholders, such as large masses of distributed end water users, first-line managers, government bureaus, etc. Figure 3 shows that a typical PSMS is composed of five basic parts that reflect the process of top-down quota setting and bottom-up data summarizing.

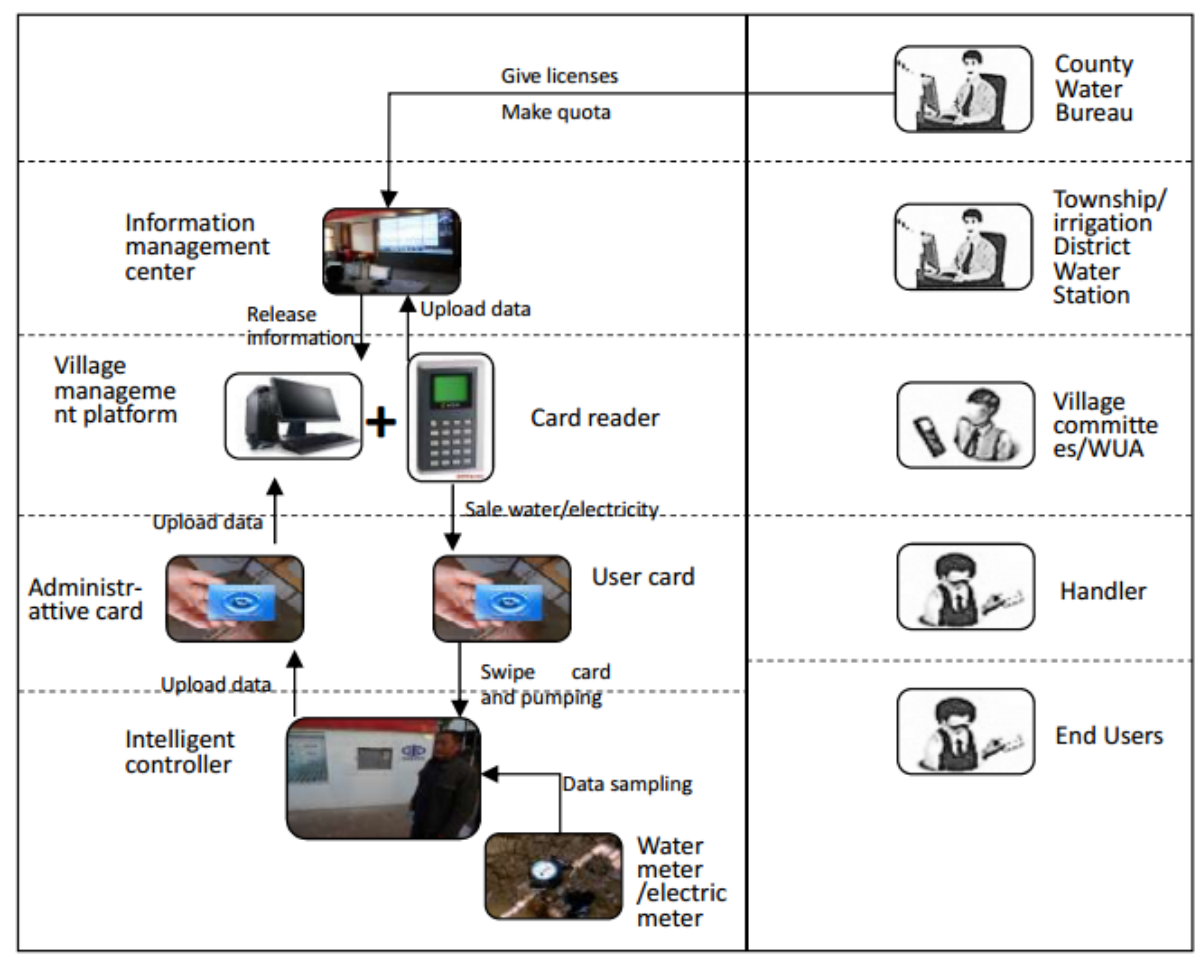

Figure 3. A typical PSMS management model in the Shiyang River Basin, Gansu Province.

- Information management center: A management center is located in one irrigation district in the western area and in one eastern area county. The center comprises servers, databases, customized software, and displays that can illustrate data processing results combined with Geographic Information System. This section can provide and display a summary of information to help local governments make decisions.

- Village management platform: Commonly, a management platform is established for a village or a Water Users Association (WUA). The primary function of the platform is to support the village committee or the WUA to sell water and electricity, charge fees, and to preliminarily track the consumption data. In Gansu Province, because the quota is divided among the end users directly by the water bureau, users can inquire about their quota on the village platform. The platform can also help the WUA understand and manage the quota usage and make adjustments. Additionally, this level is the primary supplier of terminal parts maintenance. 
- Intelligent cards, water/electric meter, and intelligent controller: These three sections are regarded as the intelligent terminal client (ITC) that works closely with end users. A meter and a controller are installed on one well. End users who extract from one well use their own intelligent card. After farmers paid their water or electricity quota, their purchasing information would be stored on the card. Farmers can use their quota by swiping the card on the controller. Quota consumption will be recorded accurately by the meter and uploaded by the controller at the same time. Constrained by the ITC, farmers cannot produce water from the well if the prepaid water/electricity has been depleted.

\subsection{Implementing Policies}

Water metering was clearly stipulated in the Water Law [46] issued in 2002 and in the China Water Conservation Technology Policy Outline [47] issued in 2005. It was established again in the No. 460 decree of the State Council [48] in 2006 that water metering shall be implemented and water users shall bear legal responsibilities for installing water metering facilities. The issuing of this decree had strengthened the water metering management. In 2011, the "most strict water resources management policy" proposed by the Central Document No. 1 put forward higher requirements for water metering and statistics management. It states that clear management tasks at all levels should be defined and that water resources metering and accounting networks overlaying all industries should be established. With most of the water production under control, basic data can be provided for the assessment of the Most Strict Water Resources Management System.

According to current policies, the exploitation well owners should cover the purchasing and installation costs of the ITC as well as the verification, maintenance, and renewal fees. However, the users will be subsidized by the local government according to local policies. The government subsidized nearly all the costs of the new facilities, especially in the primary stage of the implementation process. The system operation follows the process of applying-verifying-approving-charging if users want to purchase water or electricity. For verification, managers in the village committee/WUA and in the irrigation district will strictly verify and approve farmers' applications according to the divided quota in areas where quota management has been implemented over a long duration. However, verification is much simpler in areas where quota management is not fully implemented. The government will penalize the users if they destroy or refuse to use the system in the form of fines, administrative penalties, and criminal penalties.

A specific operation policy system had been set up in Xinjiang Province from the provincial to county levels regarded as the joint management of water and electricity. The water bureau has the executive capacity to command the electric bureau to cut off the power supply to wells under the conditions where users refuse to install the ITC, destroy or remove the ITC privately, or convert the ITC to pump over the quota. The electric bureau can turn the electricity back on only when the mentioned violations were reclaimed and the water bureau supplies the permission notice. If a short-term breakdown occurred on the meter or controller, the assistant metering method will start by converting the actual electricity consumption to groundwater consumption.

The highlight of the PSMS in the Shiyang River Basin, Gansu Province is the outstanding operation mechanism, which can be summarized as "Total amount control, quota management, distributing quota to end users, water market and trade, and water coupon circulation". Water management agencies divided a detailed quota for each industry and each crop depending on their water demand. Single farmer's water rights and the quota for one irrigation round were clearly formulated based on the land area, crop type, jurisdiction, etc., and were recorded by his own Water Rights License, Water Users' Knowledge Card, and Ledger. More detailed rules were stipulated by the local government for each aspect of water resource management, such as water right trade, water consultation, using water coupons, maintenance of the ITC, and legal responsibility. For example, there is a detailed clause on how to protect the ITC in the cold winter regarding the procedure, responsibility, supervision, and punishment. 


\subsection{PSMS Implementation Process in Six Provinces}

The literature review and field survey showed that the PSMS implementation time and progress varied in different locations (Figure 4). The first report of a PSMS to be utilized occurred in 1997 at the village level in Laiwu City, Shandong Province [49,50]. It is reported that the system was introduced into the Daxing district of Beijing at the end of 2000 and into Leting County, Hebei Province in 2001 [51,52]. The system was introduced as a pilot in Jinzhong County, Shanxi Province in 2001 [53]. However, the system remains at the pilot level in these provinces currently. The field survey showed that the implemented systems are using electricity meters and farmers swipe cards with prepaid electricity fees but not water fees in the Hebei and Shandong Provinces. Approximately 1000 wells of the total $1.1 \times 10^{4}$ wells had a PSMS installed with electricity meters in Huantai County located in the groundwater depression cone of Zibo-Weifang in Shandong Province. Through the system, managers in WUA can record an accurate electricity consumption for each user. The ITCs implemented in the Shouguang and Gaomi counties, Shandong Province also contain electricity meters only. Hebei Province incurred high costs to implement PSMSs in the past $[54,55]$. We conducted a field investigation in 15 villages of the Taocheng District and in Shenzhou County, Hengshui City, Hebei Province, where both groundwater and surface water irrigation is conducted. We determined that ITCs with electricity meters were used in only two villages. In Beijing, PSMSs have been implemented in all the districts since 2007, and meters in the ITC were upgraded from mechanical to acoustic [56,57]. However, both the direct groundwater production metering and conversion from electricity consumed to water pumped are in use, the latter of which has to be converted to water consumption using equations [58].

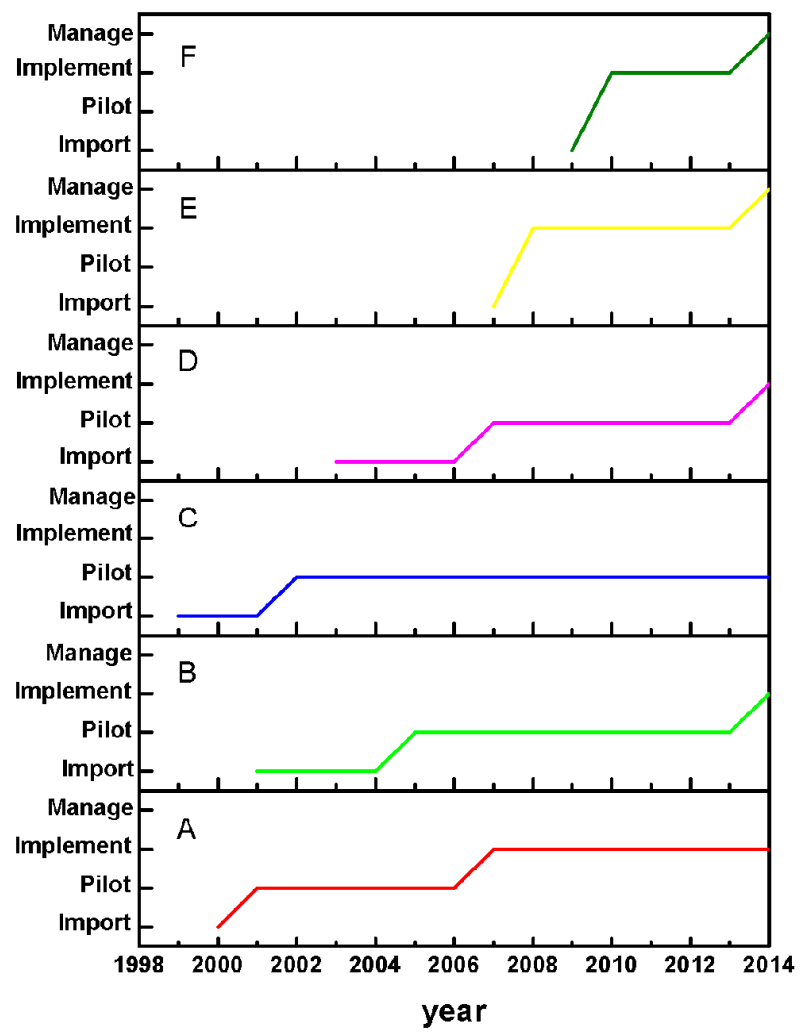

Figure 4. Differentiating the development speed in six provinces. A-Beijing, B-Hebei Province, C-Shandong Province, D-Shanxi Province, E-Gansu Province, F-Xinjiang Province.

A PSMS in the inland river basins of northwest China was introduced later than in the eastern areas but developed quickly. The Jinyang irrigation district of Wuwei City located in the upstream Shiyang River Basin is a good example. With 10 ITCs installed as a pilot in 2007, 1129 ITC sets had been immediately placed into operation covering all the wells in this district until 2008 [59]. This was a small 
portion of the basin. With the concept of "one tube well requires one permit and one meter", basin administrative agencies and local governments had begun PSMS implementation in the jurisdiction since the end of 2007. A total of 13,644 ITC sets and ten management centers were implemented during the following four years, which covered nearly $100 \%$ of the tube wells in the basin irrigation system [60,61]. A PSMS was introduced to Fukang County, Changi Prefecture, Xinjiang Province in 2009. We obtained information from interviews that the subsidy from the county finance had increased to RMB 4.25 million (approximately USD 625,000) for ITC installations at the village level, which equates to more than RMB 1 million (approximately USD 147,000) per year. All the groundwater production had been successfully metered for the 1200 wells. An ITC was planned to cover all the tube wells in four years from 2011 to 2015 in the Changji Prefecture [62].

With the goal of evaluating the implementation of the PSMS in different areas and determining the primary affecting factors, seven indexes within two main categories were selected (Table 2). The principle of the Analytic Hierarchy Process (AHP) was utilized to estimate the weight of each index with the implementation status (A) as a target level, the two main categories as a condition layer (B) and the seven indexes as a factor layer (C). Judgment matrices were constructed for each layer element corresponding to the upper layer based on the estimation of the survey group. The consistency ratio had a reasonable range, and the weight of each index was determined. The top four index rankings were $\mathrm{C} 5, \mathrm{C} 1, \mathrm{C} 6$, and $\mathrm{C} 4$. Finally, the grading scale and value $(M)$ were discussed and identified for the seven indexes.

Six typical areas were scored by the survey group for their grading value $(M)$ of each index. The comprehensive estimation results for the six areas $(R)$ can be determined according to Equation (1). A higher score indicates a better implementation level with a perfect score of five (Table 3).

$$
R=\sum_{i=1}^{n} M \times W_{i}
$$

In the early stage of development, the eastern areas that implemented the PSMS relied on their economical, technical, and information advantage. The implementation goal was to strengthen the management of groundwater pumping to save water [63-65]. The system operation is biased on the open market regulation model that uses economic leverage, such as water price, to stimulate farmer's awareness to reduce water consumption. In the second stage of development, especially after the total amount control and quota management were implemented by the Chinese government due to the severe water shortage crisis, the western areas implemented a PSMS rapidly with strict government enforcement. The model is based on the government implementing the PSMS as a management and control tool to strengthen the regulation of groundwater resources exploitation based on the concepts of total amount control and quota management $[59,66]$. Meanwhile, the market regulation model in the eastern provinces seemed to be lagging in development. 
Table 2. Selected indexes for evaluating the implementation of PSMS.

\begin{tabular}{|c|c|c|c|c|c|c|}
\hline \multirow{2}{*}{ Target Layer } & \multirow{2}{*}{ Condition Layer } & \multicolumn{2}{|l|}{ Indexes } & \multicolumn{3}{|c|}{ Grading Scale and Value } \\
\hline & & Factor Layer & $\begin{array}{c}\text { Weight } \\
W_{B i} \times W_{C j}\end{array}$ & $\begin{array}{l}\text { Good } \\
M=5\end{array}$ & $\begin{array}{c}\text { Average } \\
M=3\end{array}$ & $\begin{array}{l}\text { Weak } \\
M=1\end{array}$ \\
\hline \multirow{7}{*}{$\begin{array}{l}\text { Implementation } \\
\text { status A }\end{array}$} & \multirow{4}{*}{$\begin{array}{l}\text { Implementation } \\
\text { efficiency of the } \\
\text { government B1 }\end{array}$} & Installation proportion $\mathrm{C} 1$ & 0.2855 & $\geq 75 \%$ & $30 \%-75 \%$ & $\leq 30 \%$ \\
\hline & & Measurement object $\mathrm{C} 2$ & 0.0618 & Groundwater consumption & $\begin{array}{l}\text { Water and electricity } \\
\text { consumption }\end{array}$ & Electricity consumption \\
\hline & & Construction of a policy system C3 & 0.0323 & Perfect & $\begin{array}{c}\text { Basic } \\
\text { framework }\end{array}$ & Weak \\
\hline & & Government investment $\mathrm{C} 4$ & 0.1203 & Consistent with local economy & $\begin{array}{l}\text { Partially consistent with } \\
\text { local economy }\end{array}$ & $\begin{array}{l}\text { Inconsistent with } \\
\text { local economy }\end{array}$ \\
\hline & \multirow{3}{*}{ Implementation effect B2 } & Acknowledgements from farmers C5 & 0.2968 & $\geq 80 \%$ & $50-80 \%$ & $\leq 50 \%$ \\
\hline & & Social benefits $\mathrm{C} 6$ & 0.1247 & $\begin{array}{l}\text { Significant effect on improving the } \\
\text { working conditions of farmers and } \\
\text { labor efficiency }\end{array}$ & $\begin{array}{l}\text { Has a role in improving the } \\
\text { working conditions of farmers } \\
\text { and labor efficiency }\end{array}$ & No obvious social benefits \\
\hline & & Environmental benefits $\mathrm{C} 7$ & 0.0785 & $\begin{array}{l}\text { The groundwater level decline was } \\
\text { significantly inhibited and } \\
\text { production decreased significantly }\end{array}$ & $\begin{array}{l}\text { The groundwater level decline } \\
\text { decreased and production was } \\
\text { not significantly increased }\end{array}$ & $\begin{array}{l}\text { The groundwater level } \\
\text { continued to decline with } \\
\text { increasing production }\end{array}$ \\
\hline
\end{tabular}

Table 3. Index Classification Test Results.

\begin{tabular}{ccl}
\hline Typical Areas & $\boldsymbol{R}$ Score & Typical Characteristics of the First 4 Indexes \\
\hline Fukang County, Xinjiang Province & 4.6855 & High acknowledgment from farmers, high installation proportion, high social returns, high investment from government \\
\hline Shiyang River Basin, Gansu Province & 4.8425 & High acknowledgment from farmers, high installation proportion, high social returns, high investment from government \\
\hline Qingxu County & 2.9997 & High acknowledgment from farmers, medium installation proportion, medium social returns, medium investment from government \\
\hline Beijing City & 2.1655 & Medium acknowledgment from farmers, medium installation proportion, medium social returns, medium investment from government \\
\hline Hengshui City, Hebei Province & 2.0609 & Low acknowledgment from farmers, low installation proportion, medium social returns, high investment from government \\
\hline Depression cone of Shandong Province & 1.8203 & Low acknowledgment from farmers, low installation proportion, medium social returns, low investment from government \\
\hline
\end{tabular}




\section{PSMS Effect Evaluation and Outlook}

The primary advantage of the PSMS as a management tool is reducing groundwater production by changing the habits of water users. This study estimated the implementation advantage of PSMS. We took the effect of Qingxu County, Shanxi Province as an example.

The PSMS of Qingxu County was imported in 2007 with an ITC installed on all the 1473 tube wells in the county jurisdiction. The total cost of the system was RMB 30 million (approximately USD 4.4 million), not only for the PSMS but also for sixty solar powered observation wells. The water bureau determines each farmer's quota by the total amount index. The quota varies from area to area and depends on the land owned, the number of families, and the livestock owned. The swipe card transactions are transmitted through the internet to the Digital Water Resource Information Centre in the water bureau. This center meticulously records the number of units consumed by each farmer based on the swipe card transactions. In this procedure, the bottom-up summarization of data shows the accurate metering of agricultural groundwater consumption, and the top-down quota division achieves the direct management and control of end water users.

The effects are remarkable. The volume of groundwater consumed in Qingxu County decreased steadily from $0.59 \times 10^{8} \mathrm{~m}^{3}$ in 2004 to $0.35 \times 10^{8} \mathrm{~m}^{3}$ five years later-a decrease of $30 \%$ in a time when the demand for industrial and agricultural water was increasing [67]. The groundwater level improved from a continual decline to increasing at a rate of 1.6 to $4.8 \mathrm{~m} /$ year. The regulated PSMS encouraged the efficiency of water use and benefits and promoted the sustainable utilization of water resources. The increasing conflict between the supply and demand of water resources has been alleviated. The declining groundwater environment has recovered.

According to current plans [68], the PSMS will continue to be implemented in northern China. The Ministry of Water Resources plans to install 70,600 ITC sets in groundwater over-exploitation areas, 37,670 of which are for Hebei Province and 16,240 for Shandong Province. The comprehensive treatment of groundwater over-exploitation started in 2014 to increase the installation speed and utilization of the PSMS. It was clearly stipulated in the pilot program of 2014 that ITC should be placed into operation in all the water saving and production limiting program areas in the pilot counties. It was determined that all groundwater fees should be charged based on actual agricultural groundwater pumping volume. The volume should be metered by ITC in the scope of the program areas in the pilot counties and converted from the metered electricity consumption beyond the scope of the program areas. In the western areas where the PSMS had been widely used, the system had covered nearly all the groundwater irrigation districts. Using the Luotuocheng irrigation district in the Heihe River Basin of Gansu Province as an example, groundwater production from approximately 4000 tube wells is the primary water source in the $120 \mathrm{~km}^{2}$ area. According to the field survey conducted in September of 2014, approximately 1000 ITC sets had been installed on the wells. By May of 2015, all the wells in this district had been metered and controlled by the PSMS. In Gaomi County, Shandong Province, a cultivated field with an area of approximately $14 \mathrm{~km}^{2}$ has been controlled via the PSMS. The PSMS outlook is promising due to the enthusiasm of the local government at different levels in China. Correspondingly, more than 500 suppliers started businesses in the flourishing market [69].

\section{Shortcomings and Countermeasures}

\subsection{Initial Investments}

It is very difficult and costly to meter all the water used by farmers of a large-scale irrigation system. Major examples for metering at the level of the individual users can be found in modern piped systems in richer countries [70]. Even in modern countries, the installation of water meters to measure the volume of water consumed requires considerable initial investments [71]. The current PSMS implementation in northern China requires a significant investment. China had invested this capital, but a large problem is that the investment is from a single channel of the government. 
The Chinese government implemented a Rural Tax Reformation in 2000. An important influence of this reform was that rural water conservancy projects were less invested by the village committee and individual farmers but more so by financial investments from the central, provincial, and municipal government [72]. Direct investments from the government for water conservancy construction reached RMB 23.86 billion in 2010, which accounted for $88.13 \%$ of the total annual investment [73]. This caused PSMS investments to be rarely sourced from business channels. In the field survey, we obtained information that PSMS pilots were sustained by central and provincial financial project funds. Even though there are policies that end users should provide the cost of the PSMS, the local government must subsidize most of the ITC installation cost in the implementation stage in the western areas. The single initial investment channel increased the government's financial burden and extended the implementation period. From the perspective of water users, even if there are executive order requirements, they may not have enough enthusiasm for the investment and utilization of PSMS.

The field survey shows that new investment models regarded as Build-Operate-Transfer (BOT) and Public-Private-Partnership (PPP) had been created as trials in the Luotuocheng Irrigation District and Taocheng County. Using Taocheng County as an example, the contract price of one ITC is approximately RMB 4000-5000 per unit. The planned investment is composed of RMB 2000 from the central financial fund and the remainder from local governmental finance. For the 1600 tube wells in the county jurisdiction, the county government must fund approximately RMB 3-4 million (USD441,176) to construct the entire PSMS. In line with the BOT model, this capital will be funded by the instrument supplier and will be recovered by water fees during the operation period. Long-term planning for the system includes transmitting groundwater production data to the provincial water resources department, which requires further investment for the construction of mass transport networks. Additional investment models such as PPP are being discussed. It is beneficial to explore the BOT model under the current conditions. However, we learned that business companies do not have enough enthusiasm to join the model because of the long cost recovery time due to the currently low water fee prices.

\subsection{Policy System}

Groundwater production metering is a legal policy. One problem is that existing provisions are oriented toward the legal principles and lack specific norms and regulations. Without a policy basis, local governments have different choices in the implementation of a PSMS, forming their own methods or sidestepping significant conflicts, which causes the system operation to face a series of problems while overlooking the effects.

It is stipulated by law that the ITC should be installed and owned by the end users. This article indicates that it is illegal to punish the user if they destroy their own instruments. We do not have penalty articles for users destroying metering and monitoring facilities [74]. These shortcomings caused local governments, including Gansu and Xinjiang, to subsidize ITC installation but not pay for it directly. To encourage ITC implementation, the users who refuse to use or destroy the instrument must be penalized, even though the property belongs to the users. Due to the absence of legislation, executive punishment is the only choice but varies from province to province since the local government has much freedom in the actual operations. For example, the water bureau in Xinjiang Province used to penalize the ITC destroyer through administrative detention associated with the police, but the water bureau in Gansu Province typically cut off the power supply to the offenders.

Another shortcoming is the lack of regulations on upgrading and maintaining the ITC. Not only the initial investment but also the cost of maintenance and upgrade/renewal of the ITC in the PSMS is significant because of the large quantities. Interview data showed that the annual cost of maintenance and upgrades will be approximately RMB 1-2 million (approximately USD294,117) if all the 11,000 ITCs were equipped in Huantai County, Shandong Province. This sum was calculated based on a depreciation period of five years. Although water users are regulated to ensure appropriate facility operations, detailed rules are lacking responsibilities, procedures, and investments. Due to 
this problem, we found that local governments always sidestep this aspect in their management process. Local policy is non-specific when referring to the responsibility and investment of the system upgrade/renewal. Therefore, the flawed supporting policy system is a hidden danger for the long-term stable operation of the system.

China is a country with vast territory and numerous jurisdictions that make it difficult for a common policy to be suitable for every area. The central government should strengthen the interpretation of certain legal ideas and norms so that the local government could implement a suitable framework rather than disregarding it when exploring the policy system themselves. In addition, the top-level system construction should also be strengthened to avoid conflicts between different institutions, such as the conflict of the subsidy policy for farmers and collecting groundwater resource fees from farmers.

\subsection{Retreating of Monitoring Data}

The water end-use features are significantly different between irrigation and residential/industrial daily consumption. There is an uninterrupted and relatively flat demand curve for the latter $[41,75,76]$. However, irrigation water demand is seasonal and the demand curve is interrupted. The time scale of residential/industrial consumption is small, and demand can change at an interval of half an hour in one day. For irrigation, an integral cycle is one year in northern China. Thus, if we want to perform quantitative research on issues of PSMS operation and other derivative problems, such as assessing the effect of China's groundwater demand management policy, it is impossible unless we collect accurate PSMS production data for many years.

We conclude that data analysis research can seldom be found because of the difficulty of data collection. There are practical reasons for this situation. First, the PSMS has been operating widely for only a few years causing reliable data to be scarce. Second, much production data is dispersed in the township water station and even in the village committee due to the bottom-up version of the system. Finally, some local governments are concerned that the calculated actual exploitation would exceed the reported production amount and the total amount control index; thus, they oppose data collection by researchers.

There is no doubt that deep quantitative research will be performed with the construction and improvement of the system. A good example is Hebei Province. Groundwater production data across the entire province will be concentrated in the provincial water resources department. This will help facilitate data analysis. From the government's perspective, the confidence of the local government and public implementation will be developed by encouraging research and data analysis. Using cost-benefit analysis as an example, the results can help the government understand the benefit to the local economy, environment, and resources by implementing the PSMS and not view the system as only an administrative task.

\subsection{Unbalanced Development}

Shandong Province introduced the PSMS very early over the entire country. The ITCs currently operating are generally using electric meters that cannot directly measure groundwater withdrawal. Hebei Province was the first province to execute local groundwater production metering. Currently, however, the amount and portion of ITC installations is far less than provinces in arid and semi-arid areas. Taocheng District was one of the pilot areas for the provincial water-saving agricultural demonstration project in 2005 [77], but the county water bureau stated that no PSMS was in use in 2014. Beijing City started to install groundwater meters in 2000. After many upgrades, advanced PSMS systems are in the demonstration phase in limited areas.

Compared to provinces in arid and semi-arid areas in northwest China, provinces in the NCP fall behind in PSMS implementation, especially in the utilization of water production meters. The reasons can be summarized in three parts. First, the PSMS in the NCP was implemented earlier but restricted by early technology limitations. System upgrades require a time frame selection and additional 
investments. The provinces in northwestern areas have advantages as late stage implementers, which simplified the exploration process. Furthermore, NCP groundwater resource fees are not currently charged according to the national policy, and the groundwater production permit has yet to be strictly implemented for agricultural wells. Thus, water rights and water quota cannot be distributed to end users, which causes the PSMS to be less useful as a groundwater consumption controller. In the northwestern provinces, groundwater resource fees are generally collected according to strict policies. Thus, there is a demand for accurate measurement and consumption control. Additionally, the most important reason is the water scarcity pressure. Aquifers under the NCP still have large water storage even though the groundwater level had significantly declined. The urgency for strict management of groundwater resources is not intensive. However, in northwest China, the natural water shortage problem is aggravated by groundwater over-exploitation. Therefore, additional efforts were made during the implementation of management tools for the total amount control and quota management, with a shorter turnaround time duty circle to achieve management effects.

\subsection{Countermeasures}

PSMS implementation is currently in the beginning stage in China and is lacking references. According to the concept of the strictest water resources management, countermeasures and suggestions are provided to solve the current shortcomings as follows:

1. The irrigation strategy should be changed from single family operations to intensified agriculture. Intensified agriculture has advantages to improve management efficiency. The operators of intensified agriculture are guaranteed to cooperate with the government to conduct management policies that can expand the investment channels of the PSMS. Including the PSMS in the cost accounting management system can ensure system maintenance. It has been proven that the utilization of PSMS has better results for water savings and optimizing planting structures in the form of intensified agriculture.

2. The nation should improve policy system construction at different levels. The PSMS policy should be strengthened at the central level for a general design and at the county level for an individual design. The eastern areas should build groundwater policy reward systems by using the western experiences as a reference. Groundwater saving irrigation techniques and stakeholder participation irrigation strategies should be constructed in the eastern areas to promote water resource savings.

3. Monitoring data for groundwater consumption collected from end users should be summarized at the provincial level at a minimum. The data transmission and summarization model of the Chinese National Groundwater Monitoring Project can be used as an example. Data disclosure and analysis should also be encouraged.

\section{Conclusions}

1. There are serious water resource shortage problems in northern China. The government focused much attention on solving groundwater over-exploitation by implementing policies with direct demand management tools and economic leverage. Many resources and funds were invested in the implementation of Prepaid Smart Meter Systems for agricultural use, which charge primarily for water consumption. The Chinese government has achieved outstanding results for metering all the agricultural groundwater production in large irrigation areas. The procedure solved many difficulties and is at the head of developing countries. The goal of the implementation was to accelerate water savings and charge groundwater fees in the early stage to accurately control and manage the subsequent quota.

2. Typical areas in six provinces were selected in the northern China study area. First-hand materials were collected via methods of field surveys and interviews and second-hand materials were collected from domestic article reviews. The implementation process and status of the PSMS in 
northern China was introduced and described. We determined that the implementation speed and stage varies throughout the typical areas. Based on the qualitative analysis of the developing stage, the AHP method was utilized to perform comprehensive estimations for six typical areas of implementation. The scores of the six samples were 4.6855 for Fukang County in Xinjiang Province, 4.8425 for the Shiyang River Basin in Gansu Province, 2.9997 for Qingxu County in Shanxi Province, 2.1655 for Beijing City, 2.0609 for Hengshui City in Hebei Province, and 1.8203 for the Zibo-Weifang depression cone in Shandong Province. According to the weight of the indexes, the results showed that differences in the acknowledgment of farmers, the installation proportion of tube wells, the social benefit, and investments from the government are the major factors that influence the implementation effect.

3. Although the PSMS has produced some substantial gains in conserving groundwater, its implementation in northern China contains shortcomings, such as an imperfect policy system, hardware reliability, etc. Additional progress should be included in the legislation and institutional construction to achieve management targets. A cost-benefit analysis and effect should be evaluated to support the administrative governance of local agencies, especially for quantitative data analysis.

Acknowledgments: This study was supported by the Shandong Groundwater Management, Allocation Project subsidized by the Asian Development Bank (P47047-PRC) and the National Key Research and Development Program of the Ministry of Science and Technology of the People's Republic of China, entitled water resources efficient development and utilization (No. 2017YFC0406106). The authors would like to thank all the domestic reviewers for their valuable description and comments, which led to the improvement of the presentation of this paper.

Author Contributions: Jingli Shao and Frank van Steenbergen suggested the idea. In addition, Jingli Shao organized the field survey and Frank van Steenbergen supplied materials from the project of Shanxi province. Xiaowei Wang managed the paperwork and wrote the manuscript. Jingli Shao and Qiulan Zhang revised and improved the manuscript.

Conflicts of Interest: The authors declare no conflict of interest.

\section{References}

1. Jiang, Y. China's water scarcity. J. Environ. Manag. 2009, 90, 3185-3196. [CrossRef] [PubMed]

2. Yang, H.; Zhang, X.H.; Zehnder, A.J.B. Water scarcity, pricing mechanism and institutional reform in northern China irrigated agriculture. Agric. Water Manag. 2003, 61, 143-161. [CrossRef]

3. Neven, K. Groundwater Resources: Sustainability, Management, and Restoration; McGraw-Hill Professional Publishing: New York, NY, USA, 2009; pp. 28-30.

4. Bulletin for China's Water Resources (2003-2014). Ministry of Water Resources of the People's Republic of China: Beijing, China. Available online: http://www.mwr.gov.cn/zwzc/hygb/szygb (accessed on 28 August 2015). (In Chinese)

5. Jin, L.S.; Young, W.R. Water use in agriculture in China: Importance, challenges, and implications for policy. Water Policy 2001, 3, 215-228. [CrossRef]

6. Kuang, W.; Hu, Y.J.; Dai, X.Q.; Song, X.Y. Investigation of changes in water resources and grain production in China: Changing patterns and uncertainties. Theor. Appl. Climatol. 2015, 122, 557-565. [CrossRef]

7. Cao, G.L.; Zheng, C.M.; Scanlon, B.R.; Liu, J.; Li, W.P. Use of flow modeling to assess sustainability of groundwater resources in the north China plain. Water Resour. Res. 2013, 49, 159-175. [CrossRef]

8. Shao, J.L.; Cui, Y.L.; Hao, Q.C.; Han, Z.; Cheng, T.P. Study on the estimation of groundwater withdrawals based on groundwater flow modeling and its application in the north China plain. J. Earth Sci. 2014, 25, 1033-1042. [CrossRef]

9. Chen, J.Y. Holistic assessment of groundwater resources and regional environmental problems in the north China plain. Environ. Earth Sci. 2010, 61, 1037-1047. [CrossRef]

10. Wu, M.; Wu, J.F.; Liu, J.; Wu, J.C.; Zheng, C.M. Effect of groundwater quality on sustainability of groundwater resource: A case study in the north China plain. J. Contam. Hydrol. 2015, 179, 132-147. [CrossRef] [PubMed]

11. Davidsen, C.; Liu, S.; Mo, X.; Rosbjerg, D.; Bauergottwein, P. The cost of ending groundwater overdraft on the north China plain. Hydrol. Earth Syst. Sci. 2015, 12, 5931-5966. [CrossRef] 
12. Guo, H.; Wang, L.; Cheng, G.; Zhang, Z. Groundwater-abstraction induced land subsidence and groundwater regulation in the North China Plain. In Proceedings of the International Association of Hydrological Sciences, Gottingen, Germany, 12 November 2015; Daito, K., Galloway, D., Eds.; Copernicus GmbH: Gottingen, Germany, 2015.; pp. 17-21.

13. Giordano, M. Agricultural water policy in China: Challenges, issues, and options. Water Policy 2007, 9, 1-9. [CrossRef]

14. Liu, C.M.; Xia, J. Water problems and hydrological research in the yellow river and the Huai and Hai river basins of China. Hydrol. Process. 2004, 18, 2197-2210. [CrossRef]

15. Chen, X.; Devineni, N.; Lall, U.; Hao, Z.; Dong, L.; Ju, Q.; Wang, J.; Wang, S. China's water sustainability in the 21st century: A climate informed water risk assessment covering multi-sector water demands. Hydrol. Earth Syst. Sci. 2013, 10, 11129-11150. [CrossRef]

16. Wang, J.X.; Huang, J.K.; Rozelle, S.; Huang, Q.Q.; Blanke, A. Agriculture and groundwater development in northern China: Trends, institutional responses, and policy options. Water Policy 2007, 9, 61-74. [CrossRef]

17. Ji, X.B.; Kang, E.S.; Chen, R.S.; Zhao, W.Z.; Zhang, Z.H.; Jin, B.W. The impact of the development of water resources on environment in arid inland river basins of hexi region, northwestern China. Environ. Geol. 2006, 50, 793-801. [CrossRef]

18. Qi, F.; Cheng, G.D. Current situation, problems and rational utilization of water resources in arid north-western China. J. Arid Environ. 1998, 40, 373-382. [CrossRef]

19. Chen, Y.M.; Chen, Y.P.; Xu, C.C.; Ye, Z.X.; Li, Z.Q.; Zhu, C.G.; Ma, X.D. Effects of ecological water conveyance on groundwater dynamics and riparian vegetation in the lower reaches of tarim river, China. Hydrol. Process. 2010, 24, 170-177. [CrossRef]

20. Kundzewicz, Z.W.; Mata, L.J. Freshwater resources and their management. In Climate Change 2007: Impacts, Adaptation, and Vulnerability; IPCC, Ed.; Cambridge University Press: Cambridge, UK, 2007; pp. 180-181.

21. Seckler, D.; Amarasinghe, U.; Molden, D.; De Silva, R.; Barker, R. World Water Demand and Supply, 1990 to 2025: Scenarios and Issues; International Water Management Insitute: Colombo, Sri Lanka, 1998; p. 1.

22. Rijsberman, F.R. Water scarcity: Fact or fiction? Agric. Water Manag. 2006, 80, 5-22. [CrossRef]

23. Mancosu, N.; Snyder, R.; Kyriakakis, G.; Spano, D. Water scarcity and future challenges for food production. Water 2015, 7, 975-992. [CrossRef]

24. Kulkarni, H.; Shankar, P.S.V.; Deolankar, S.B.; Shah, M. Groundwater demand management at local scale in rural areas of india: A strategy to ensure water well sustainability based on aquifer diffusivity and community participation. Hydrogeol. J. 2004, 12, 184-196. [CrossRef]

25. Pike, C.W. Sacramento implements guidance for river, growth and demand management. In Water Science and Technology: Water Supply; Cubillo, F., Ed.; IWA Publishing: London, UK, 2005; Volume 3-4, pp. 241-248.

26. Salman, M.; Mualla, W. Water demand management in syria: Centralized and decentralized views. Water Policy 2008, 10, 549-562. [CrossRef]

27. Qin, C.B. Mitigating China's Water Scarcity and Pollution: Environmental and Economic Accounting, Modeling and Policy Analysis. Ph.D. Thesis, University of Twente, Enschede, The Netherlands, November 2011.

28. Wang, H. Assessing the economic impact of north China's water scarcity mitigation strategy: A multi-region, water-extended computable general equilibrium analysis. Water Int. 2013, 38, 701-723.

29. Shen, D.J. Groundwater management in China. Water Policy 2015, 17, 61-82. [CrossRef]

30. The State Council. Opinions of the State Council on the Implementation of the Most Strict Water Resources Management Policy. Available online: http://www.gov.cn/zwgk/2012-02/16/content_2067664.htm (accessed on 12 January 2012). (In Chinese)

31. General Office of the People's Government of Hebei Province; Hebei Provincial Bureau of Statistics. Statistical Yearbool 2013 for Rural Aeras of Hebei Province; China Statistics Press: Beijing, China, 2014; p. 334. (In Chinese)

32. Food and Agriculture Organization of the United Nations. Technology-Based Water Resources Management. Available online: http:/ /www.asia-water.org/water-intervention-themes-all/97-technology-based-waterresources-management/181-technology-based-water-resources-management (accessed on 4 March 2014). (In Chinese)

33. Jahromi, H.N.; Hamedani, M.J.; Dolatabadi, S.F.; Abbasi, P. Smart energy and water meter: A novel vision to groundwater monitoring and management. In Procedia Engineering; Brunone, B., Giustolisi, O., Ferrante, M., Laucelli, D., Meniconi, S., Berardi, L., Campisano, A., Eds.; Elsevier Science BV: Amsterdam, The Netherlands, 2014; Volume 70, pp. 877-881. 
34. Zaman, A. Replication of the Barind Model to Muhuri Irrigation Project. In Proceedings of the Moving from Water Problems to Water Solutions: Research Needs Assessment for the Eastern Gangetic Plains, New Delhi, India, 7-8 May 2013; International Water Management Institute: New Delhi, India, 2013.; pp. 82-85.

35. Barind Multipurpose Development Authority. Smart Card Based Prepaid Pump. Available online: http:/ /bmda.gov.bd/bmda_eng/prepaidmeter.php (accessed on 8 March 2015).

36. Zekri, S. Controlling groundwater pumping online. J. Environ. Manag. 2009, 90, 3581-3588. [CrossRef] [PubMed]

37. Das, A. The political economy of metering agricultural tube wells in west Bengal, India. Water Int. 2014, 39, 671-685.

38. Shah, T.; Bhatt, S.; Shah, R.K.; Talati, J. Groundwater governance through electricity supply management: Assessing an innovative intervention in Gujarat, western India. Agric. Water Manag. 2008, 95, 1233-1242. [CrossRef]

39. Davies, K.; Doolan, C.; Robin, V.D.H.; Shi, R. Water-saving impacts of smart meter technology: An empirical 5 year, whole-of-community study in Sydney, Australia. Water Resour. Res. 2014, 50, 7348-7358. [CrossRef]

40. Nguyen, K.A.; Stewart, R.A.; Zhang, H. An autonomous and intelligent expert system for residential water end-use classification. Expert Syst. Appl. 2014, 41, 342-356. [CrossRef]

41. Mckenna, S.A.; Fusco, F.; Eck, B.J. Water demand pattern classification from smart meter data. In Procedia Engineering; Brunone, B., Giustolisi, O., Ferrante, M., Laucelli, D., Meniconi, S., Berardi, L., Campisano, A., Eds.; Elsevier Science BV: Amsterdam, The Netherlands, 2014; Volume 70, pp. 1121-1130.

42. Beal, C.D.; Stewart, R.A.; Fielding, K. A novel mixed method smart metering approach to reconciling differences between perceived and actual residential end use water consumption. J. Clean. Prod. 2013, 60, 116-128. [CrossRef]

43. The Organisation for Economic Co-Operation and Development. Oecd Environmental Performance Reviews China; OECD Publishing: Pairs, France, 2007.

44. Shi, Y.L. Study on Reasonable Allocation of Agricultural Resource and Improvement of the Comprehensive Productivity; China Agricultural Press: Beijing, China, 2008. (In Chinese)

45. Zheng, C.M.; Liu, J.; Cao, G.L.; Kendy, E.; Wang, H.; Jia, Y.W. Can China cope with its water crisis?-Perspectives from the north China plain. Ground Water 2010, 48, 350-354. [CrossRef] [PubMed]

46. The Standing Committee of the Ninth National People's Congress. Water Law of the People's Republic of China (Revised). Available online: http://law.npc.gov.cn:87/page/browseotherlaw.cbs?rid=en\&bs= 105069\&anchor=0\#go0 (accessed on 29 August 2002). (In Chinese)

47. National Development and Reform Commission; Ministry of Science and Technology; Ministry of Water Resources; Ministry of Construction; Ministry of Agriculture. China Water Conservation Technology Policy Outline. Available online: http://bgt.ndrc.gov.cn/zcfb/200506/t20050602_500425.html (accessed on 21 April 2005). (In Chinese)

48. Council, T.S. Regulations on Management of Water Abstraction Permission and Collection of Water Resources Fees. Available online: http:/ /law.npc.gov.cn:87/page/browseotherlaw.cbs?rid=2\&bs=223453\&anchor= 0\#go0 (accessed on 15 April 2005). (In Chinese)

49. Chen, B.J.; Lin, H.; Xie, L.; Zhang, K.Y. Development and promotion of irrigation wells automated control system. Water Resour. Sci. Technol. Shandong 1998, 4, 73-74. (In Chinese).

50. Bian, J. "Precision farming" is turned into a reality. Xin Nongcun 1999, 4, 4. (In Chinese).

51. Han, Z.W. Countermeasures of water resources issues in daxing district. Beijing Water Resour. 2001, 6, 13. (In Chinese).

52. Zhang, W.Q. Management and application of agricultural irrigation water metering in laoting county, Hebei. China Water Resour. 2006, 7, 69. (In Chinese).

53. Liu, Y.X. The IC card measure system and its application in the well irrigation. Shanxi Hydrotech. 2010, 1, 69-70. (In Chinese).

54. Wu, B.G. The test model spread of the smart metering IC card control technology for agricultural irrigation. Water Sci. Eng. Technol. 2008, 6, 68-69. (In Chinese).

55. Zhao, Y.; Wang, Y.K.; Zhang, S.J.; Meng, X.Q. Analysis of irrigation water quantity differences between farmers in the well-irrigating areas of Hebei plain. Water Sav. Irrig. 2007, 2, 7-9. (In Chinese).

56. Li, J.H.; Di, S.C. Countermeasure of the accurate water quantity measuring system for existence probems of agricultural irrigation in Beijing. Beijing Water Resour. 2013, 2, 5-8. (In Chinese).

57. Shao, Y.Z. Practice and discussion of agricultural water metering management system construction in Shunyi district. China Water Resour. 2014, 17, 42-43. (In Chinese). 
58. Yin, S.Y.; Wu, W.Y.; Liu, H.L.; Sun, Z.H.; Qi, X.H.; Yuan, G.X. Experiments on conversion coefficient between electricity consumed and water pumped for agricultural wells in Beijing plain. J. Drain. Irrig. Mach. Eng. 2014, 11, 998-1004. (In Chinese).

59. Huang, Y. Exploration of practicing on intelligent water metering facilities installation and management of the groundwater electromechanical wells in Jinyang irrigation district, Liangzhou district. In Proceedings of the 2009 Academic Conference of Gansu Province, Zhangye, Gansu, China, 1 September 2009; Technology Association of Gansu Province: Zhangye, Gansu, China, 2009.; pp. 315-320. (In Chinese)

60. Xiong, W. On the basic functions and technical requirements for agricultural irrigation groundwater smart metering facilities. Water Sav. Irrig. 2011, 6, 63-64. (In Chinese).

61. Zhao, X.X.; Feng, G.H.; Cao, J.Y. Management and operation of water control intelligent metering facilities of wells in Shiyang river basin. Shanxi Water Resour. 2009, z2, 101-102. (In Chinese).

62. Wang, Q.D. Main approach of intelligent metering of electromechanical wells in Changji. Water Adm. Water Resour. Manag. 2011, 5, 54-55. (In Chinese).

63. Zhang, L.J.; Wang, J.X. Application of intelligent IC card system in electromechanical well irrigation and its effect. J. Econ. Water Resour. 2005, 23, 42-44. (In Chinese).

64. Li, Z.C.; Zhou, C.X.; Zhang, Z.; Song, H.Y. Ic smart card management system in water saving irrigation. Water Sav. Irrig. 1999, 4, 30. (In Chinese).

65. Han, X.Z.; Zhang, L.M.; Pang, Y.S. Rf IC card intelligent control system in agricultural irrigation. Henan Water Resour. 2004, 5, 43. (In Chinese).

66. Zhong, Y.X.; Li, P.L.; Chen, B.; Hou, M.P. Exploration for self-contained agricultrual water-saving practice in Qingxu, Shanxi. China Rural Water Hydropower 2013, 10, 24-26. (In Chinese).

67. Fan, G.S.; Van Steenbergen, F.; Zhang, W.Z. Climate Change Adaptation Through Groundwater Management of Shanxi Province, People's Republic of China, Final report 0188-PRC ADB Grant Project. Available online: http://metameta.nl/wp-content/uploads/2013/11/Grant_Project_0188-PRC_Final_Report_SF.pdf (accessed on August 2017).

68. China Renewable Energy Engineering Institute; Planning and Designing Administration for South-to-North Water Diversion. Overall Scheme of Groundwater Abstraction Reducing of East E Central Reception Regions of South-to-North Water Diversion; China Renewable Energy Engineering Institute: Beijing, China, 2010. (In Chinese)

69. Wang, W.G. Status and Development Trend of Smart Meter Industry. In Proceedings of the Fifth Water Industry Flow Instrument Selection and Application Technology Conference, Changsha, Hunan, China, 31 October 2012; China Urban Water Association: Changsha, Hunan, China, 2012. (In Chinese)

70. Vos, J.; Vincent, L. Volumetric water control in a large-scale open canal irrigation system with many smallholders: The case of chancay-lambayeque in peru. Agric. Water Manag. 2011, 98, 705-714. [CrossRef]

71. Mohapatra, S.P.; Mitchell, A. Groundwater demand management in the great lakes basin-Directions for new policies. Water Resour. Manag. 2009, 23, 457-475. [CrossRef]

72. Ma, C.X.; Han, S.J. Impact of rural tax for fee reform on irrigation project development and calculation and collection of agricultural water fee and corresponding measures. China Water Resour. 2005, 22, 46-48. (In Chinese).

73. Li, Q.; Liu, Y.P. Development of water conservancy investment and financing mechanism innovation in China. Shandong Agric. Sci. 2013, 45, 147-151. (In Chinese).

74. Zhu, F.R. On the legal issues of the installation of water metering facilities. Jiangsu Water Resour. $2003,1,30$. (In Chinese).

75. Fróes Lima, C.A.; Portillo Navas, J.R. Smart metering and systems to support a conscious use of water and electricity. Energy 2012, 45, 528-540. [CrossRef]

76. Gurung, T.R.; Stewart, R.A.; Sharma, A.K.; Beal, C.D. Smart meters for enhanced water supply network modelling and infrastructure planning. Resour. Conserv. Recycl. 2014, 90, 34-50. [CrossRef]

77. Wang, F.Q.; Gao, M.S.; Jin, J.B. Monitoring facilities of water-saving irrigation used in well irrigation croplands-the lifting water controller with IC card in use for pumping well. South North Water Transf. Water Sci. Technol. 2006, 4, 62-64. (In Chinese).

(C) 2017 by the authors. Licensee MDPI, Basel, Switzerland. This article is an open access article distributed under the terms and conditions of the Creative Commons Attribution (CC BY) license (http:/ / creativecommons.org/licenses/by/4.0/). 